\title{
Extramedullary haemopoietic tumours complicating polycythaemia vera
}

\author{
P K MAcCALlUM,* M J NEWBOULD, $\dagger$ P S SAMBROOK, $\ddagger$ I E BURTON* \\ From the Departments of *Haematology, $\nmid$ Histopathology, and $\ddagger$ Diagnostic Radiology, Withington Hospital, \\ Manchester
}

SUMMARY A 52 year old man with newly diagnosed polycythaemia vera in proliferative phase developed widespread extramedullary haemopoiesis (EMH), and died as a result of cervical cord compression. At necropsy, microscopic areas of primitive cells characteristic of granulocytic sarcoma were found within a large tumour of EMH in the right retroperitoneal region. Ultrastructural analysis showed unusual hexagonal inclusions within the cytoplasm of these primitive cells.

Clinicians should be aware of the possibility of discrete haemopoietic tumours, whether EMH or granulocytic sarcoma, in patients with polycythaemia vera as well as in other myeloproliferative disorders.

Polycythaemia vera is a myeloproliferative disorder of clonal origin arising at the level of the pluripotential haemopoietic stem cell' and resuiting in neoplastic proliferation of erythroid, myeloid, and megakaryocytic elements in the bone marrow; an increased red blood cell mass; and, usually, raised blood counts of the three major haemopoietic cell lines.

Extramedullary haemopoiesis (EMH) occurring in liver and spleen is a well recognised complication of myeloproliferative disorders, particularly myelofibrosis, ${ }^{2}$ but discrete tumours of EMH are rare and particularly so in the proliferative phase of polycythaemia vera. ${ }^{34}$

Polycythaemia vera commonly transforms from a proliferative into a spent or myelofibrotic stage, ${ }^{2}$ but acute myeloblastic leukaemia (AML) can also develop, although this is more common after treatment with alkylating agents or radioactive phosphorus $\left({ }^{32} \mathrm{p}\right)$ than after venesection alone. ${ }^{5}$ Granulocytic sarcomas, which are tumours composed of immature cells of the myeloid series, are uncommon, but do arise in AML and myeloproliferative disorders, particularly in chronic granulocytic leukaemia (CGL) ${ }^{67}$ They are very rare in polycythaemia vera, ${ }^{7}$ but in this paper we describe a patient with proliferative phase disease in whom such a problem arose.

\section{Case report}

A 52 year old man with a five month history of lower Accepted for publication 9 February 1988 back pain, radiating to the right thigh, was admitted to hospital. For two months he had been aware of a tender swelling in the right loin, at the site of attachment of a right leg prosthesis, which he had worn since a traumatic avulsion of the leg $15 \mathrm{~cm}$ below the greater trochanter, in a road traffic accident eight years previously. Examination showed that he had no hepatosplenomegaly, but there was a diffuse tender swelling affecting the right loin.

Full blood count was as follows: haemoglobin 201 $\mathrm{g} / \mathrm{l}$; packed cell volume 0.65 ; mean cell volume $73 \mathrm{fl}$; white cell count $17.5 \times 10^{9} / 1$ (neutrophils $16.45 \times 10^{9} /$ 1 , lymphocytes $0.88 \times 10^{9} / 1$, monocytes $0.18 \times 10^{9} / 1$ ); and a platelet count of $185 \times 10^{9} / 1$. There were no circulating primitive cells. His red cell volume, measured isotopically, was $51.3 \mathrm{ml} / \mathrm{kg}$ (normal 30 (2 SD 5) $\mathrm{ml} / \mathrm{kg}$ ) and plasma volume $54.6 \mathrm{ml} / \mathrm{kg}$ (normal $45(5) \mathrm{ml} / \mathrm{kg}$ ). His bone marrow was severely hypercellular with an increase in erythroid, myeloid, and megakaryocytic activity; iron stores were virtually absent. A trephine biopsy specimen showed panmyelosis without a large increase in reticulin. Serum vitamin B12 concentration was greater than $2000 \mathrm{ng} / 1$ (normal 150-1000 ng/l) and B12 binding capacity was $3240 \mathrm{ng} / \mathrm{l}$ (normal $600-2200 \mathrm{ng} / \mathrm{l}$ ). On the basis of these results, proliferative phase polycythaemia vera was diagnosed.

A computed tomography scan of the abdomen showed a swelling of the right iliopsoas, posterior spinal, and gluteus medius muscles which had the attenuation of normal muscle (fig 1). This was initially 


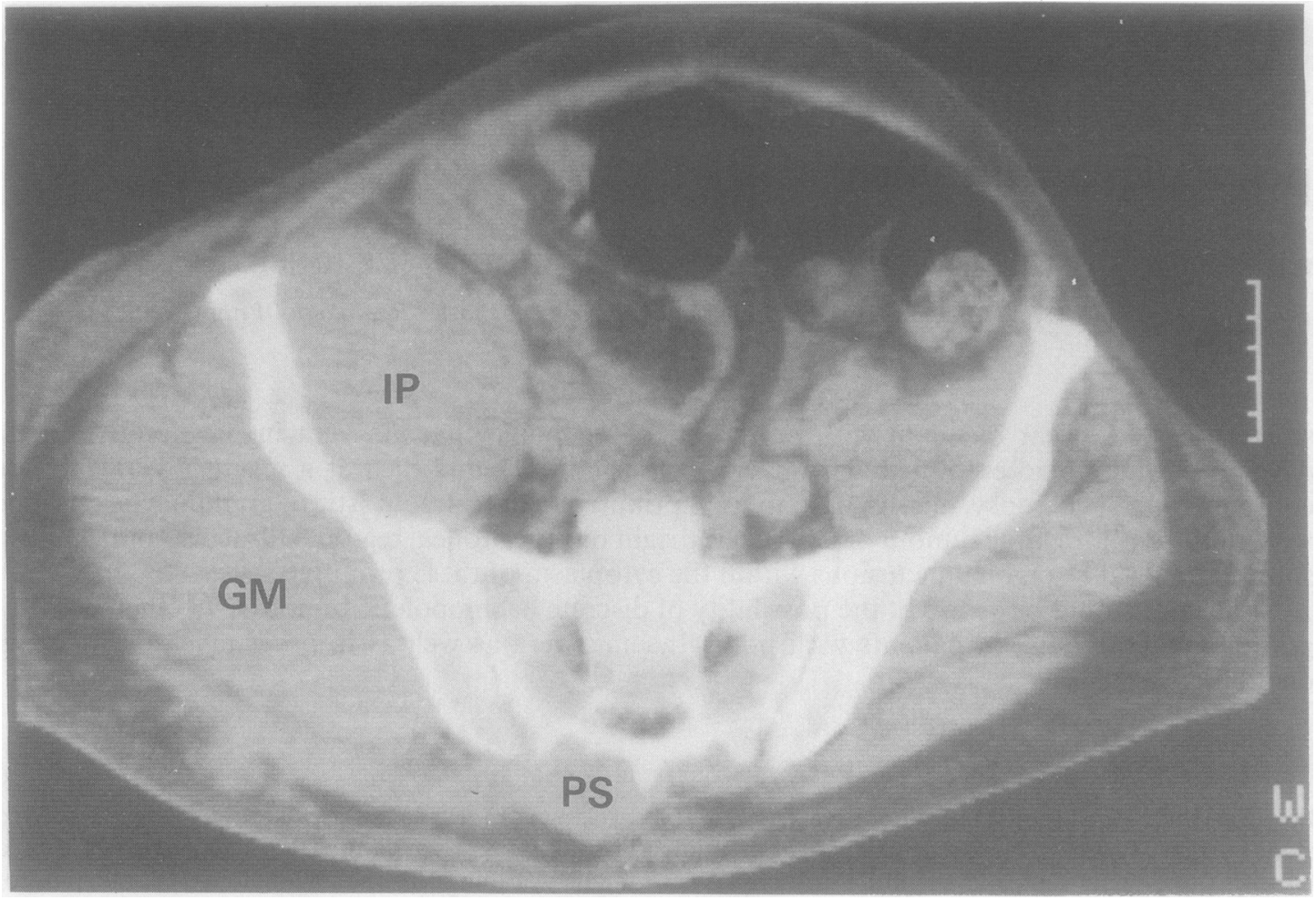

Fig 1 Computed tomography scan of abdomen showing swelling of right iliopsoas (IP), posterior spinal (PS), and gluteus medius (GM) muscles.

presumed to be due to an organised haematoma. The patient was treated with venesection $(3 \mathrm{U})$ and ${ }^{32} \mathrm{P}(300$ $\mathrm{MBq})$. His haemoglobin concentration fell over two weeks to $160 \mathrm{~g} / \mathrm{l}$, packed cell volume to $0 \cdot 51$, and there was a slight reduction in the right loin swelling.

Despite this improvement, three weeks after admission he complained of increasingly severe neck pain and rapidly developed signs of a progressive quadraplegia below the C6 level, with sensory loss below T3. After a myelogram a computed tomography scan of the cervical region showed a complete extradural block with no evidence of bone destruction at the $\mathrm{C4}-5$ level.

Histological examination of a Tru-cut biopsy specimen taken from the right loin swelling at this stage showed appearances of extramedullary haemopoiesis with myeloid, erythroid, and megakaryocytic lines all present (fig 2), though an excess of immature cells was present in some microscopic fields. On the assumption that a similar pathological process was responsible for the cord compression, the patient was treated with radiotherapy to the cervical spine in a single dose of $1500 \mathrm{cGy}$, but he continued to deteriorate and died within a month of his initial presentation from respiratory and cardiac arrest.

\section{Pathology}

Examination of the visceral organs showed that there was moderate hepatosplenomegaly, the liver weighing $2596 \mathrm{~g}$ and the spleen $554 \mathrm{~g}$; and that foci of haemopoietic tissue were present within the sinusoids of the liver and the red pulp of the spleen. Within the spinal canal there was a soft, pale, fleshy extradural mass extending down about $10 \mathrm{~cm}$ from the level of $\mathrm{C4}$ vertebra. Another notable feature was a large, ill defined indurated mass, extensively affecting the retroperitoneal tissues on the right, including the paraspinal tissues, the perirenal area, and the right psoas muscle. The exact dimensions of the mass were difficult to assess, but it did not extend to the spinal canal nor into the right thigh. The affected tissues were firm and adherent to each other and small focal areas of necrosis were present within the right psoas. The abdominal aorta and, to a lesser extent, the thoracic aorta were encased in a nodular pale mass of tissue leading to compression of the inferior vena cava. 


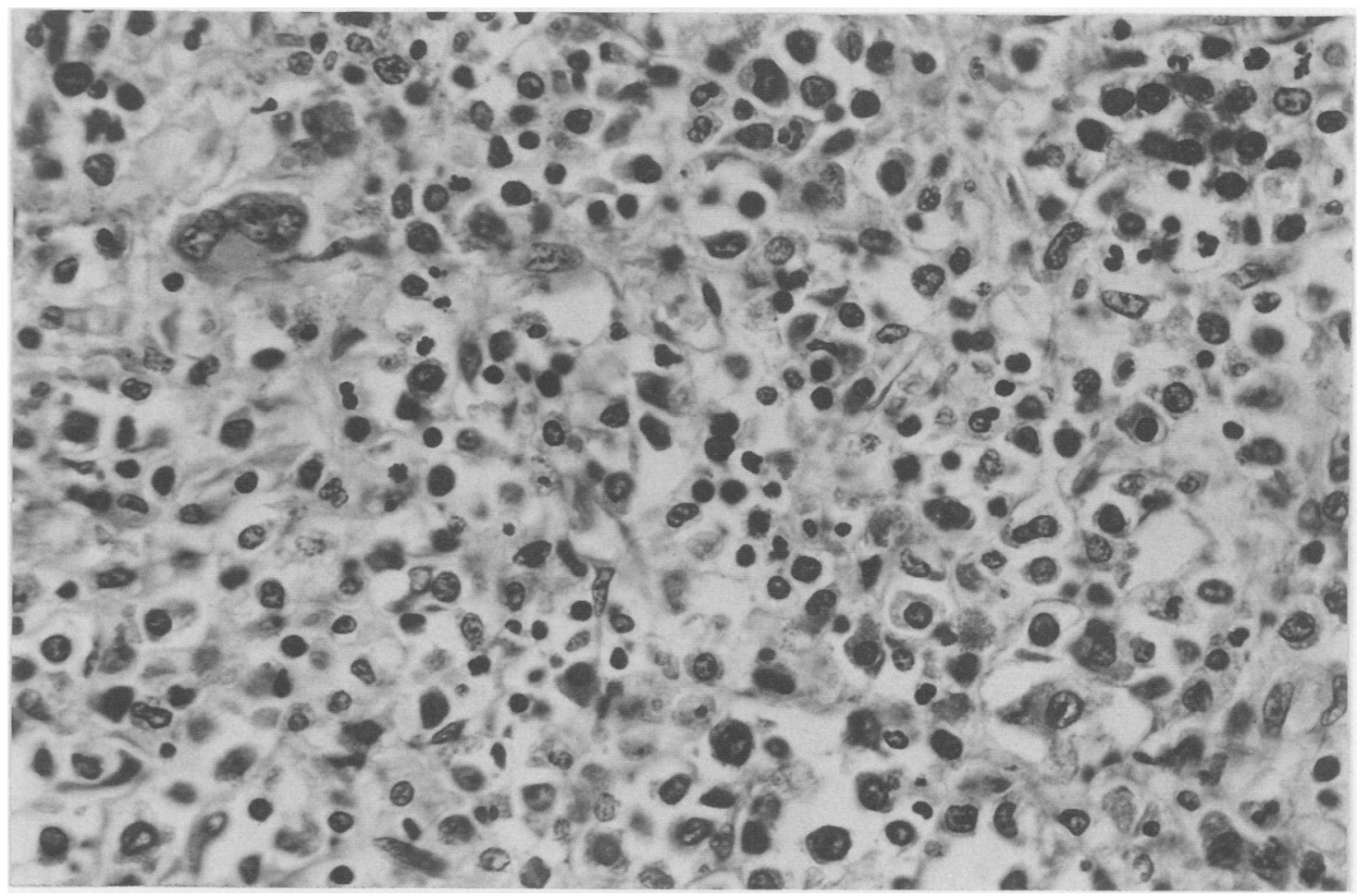

Fig 2 Tru-cut biopsy specimen of right retroperitoneal mass showing extramedullary haemopoiesis. (Haematoxylin and eosin.)

\section{LIGHT MICROSCOPICAL FINDINGS}

The mass within the spinal cord was composed of haemopoietic tissue containing myeloid, erythroid, and megakaryocytic lines showing maturation, though in some microscopic foci immature forms predominated. The para-aortic and retroperitoneal masses were composed largely of mature haemopoietic tissue, but the infiltrate was monomorphic within the right psoas muscle (fig 3). It was composed of round cells with a high nuclear:cytoplasmic ratio and stained negatively with periodic acid Schiff, Congo red, and Giemsa. Five to $10 \%$ of the cells stained positively with anti-muramidase and a similar proportion showed some positivity with the chloracetate esterase technique. Intracytoplasmic inclusions were not visible on light microscopy. The tumour was deemed to be a granulocytic sarcoma.

\section{ULTRASTRUCTURAL FINDINGS}

The tumour within the right psoas muscle was examined by transmission electron microscopy. Post mortem autolysis was seen in all fields examined; cell membranes were absent and nuclear envelopes showed ballooning. Some clinically important cellular details could be seen.
The cells were predominantly of one type and were interspersed in a collagen matrix. Membrane bound electron dense granules of about $600 \mathrm{~nm}$ mean diameter were seen within the cytoplasm of all cells examined, some showing an electron lucent halo with an inner granular structure. Inclusions of hexagonal shape were also present in the cytoplasm of some cells. Their size varied from 1.5 to $3.0 \mu \mathrm{m}$ in diameter and from 3.0 to $8.0 \mu \mathrm{m}$ in length (fig 4). The inclusions were of medium electron density and were homogeneous when seen in hexagonal outline, but in the other plane of section, crystal lattice planes with an approximate $25 \mathrm{~nm}$ spacing were apparent. The degree of autolysis made it impossible to assess if they were membrane bound. Occasional electron dense granules were seen within the inclusions.

The presence of cytoplasmic granules within the tumour cells seemed to confirm their identity as myeloblasts and provided further evidence that the tumour should be termed a granulocytic sarcoma.

\section{Discussion}

As far as we know this is the first case report of spinal cord compression due to EMH occurring in a patient 


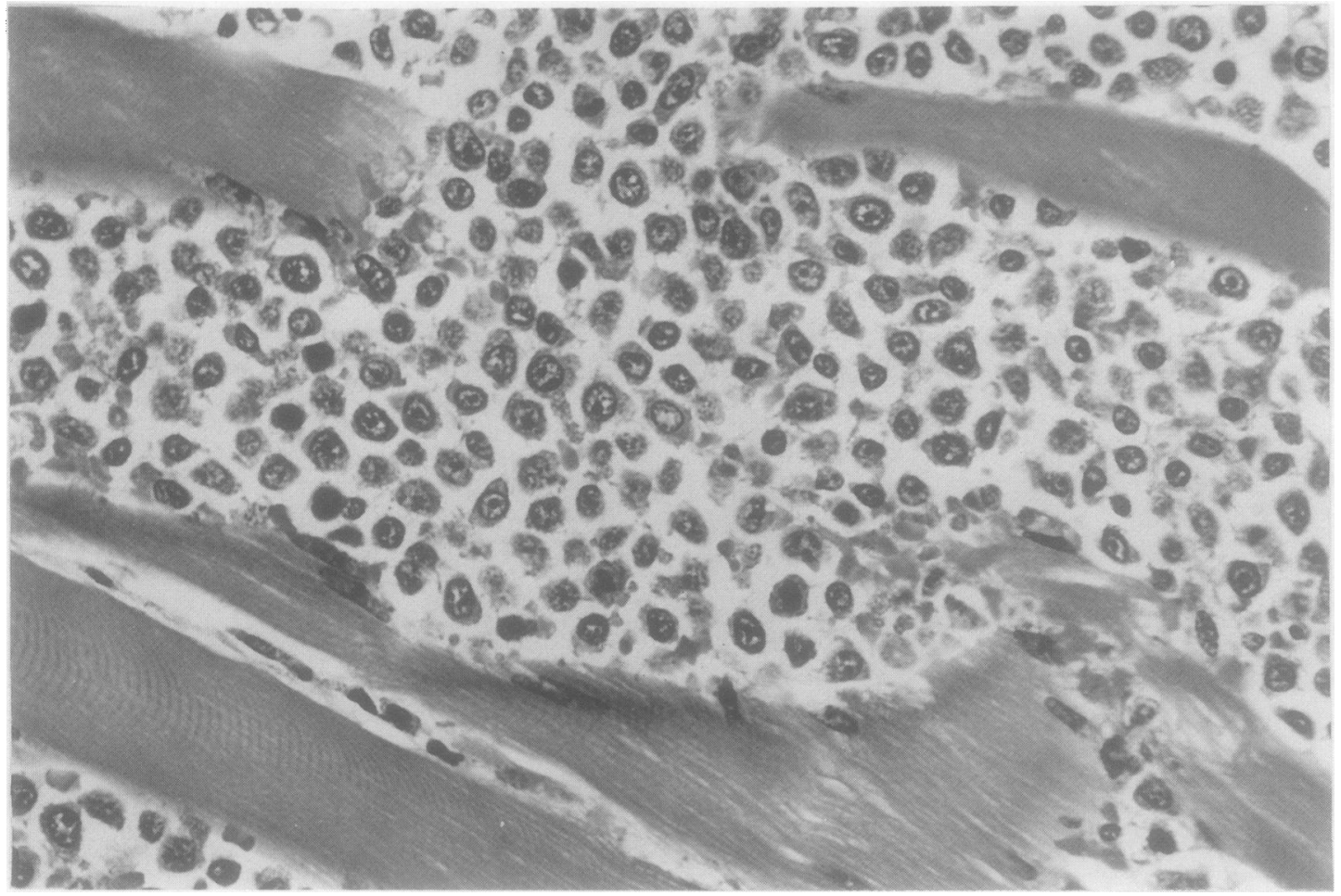

Fig 3 Mass in right psoas muscle showing granulocytic sarcoma. (Haematoxylin and eosin.)

with polycythaemia vera without accompanying myelofibrosis. It is the fourth case in which granulocytic sarcoma developed in polycythaemia vera, but recognition of leukaemic transformation within EMH in this disease is new, as is the description of hexagonal crystals within the cytoplasm of the tumour cells.

Although EMH has been described in various anatomical sites in other conditions, ${ }^{2}$ it is not usually extensive in uncomplicated polycythaemia vera, though it can be found in splenic biopsy specimens taken early in the course of the disease. ${ }^{2}$ Pettit et al suggest that no, or only minimal, extramedullary erythropoiesis occurs in uncomplicated polycythaemia vera and that its demonstration in such a patient is an indication that the condition is undergoing transformation to myelofibrosis or to "transitional myeloproliferative disorder". ${ }^{8}$ Our case lacked features suggestive of transformation, such as splenomegaly, a leucoerythroblastic blood picture, or increased reticulin in the bone marrow trephine biopsy specimen. The polycythaemia vera seemed to be in proliferative phase and yet the EMH found at necropsy was extensive.
There have been 32 reported cases of spinal cord compression due to EMH. ${ }^{9-13}$ Most of these cases occurred in hereditary and refractory anaemias, particularly thalassaemia major and intermedia (12 cases), and in myeloproliferative disorders, most commonly myelofibrosis, both primary and post-polycythaemic. There is only one previous case report of spinal cord compression due to EMH complicating polycythaemia vera, ${ }^{3}$ and this occurred in a patient with myelofibrosis which preceded the onset of polycythaemia. Intracranial meningeal disease with EMH has also been described in association with myeloproliferative disorders-predominantly myelofibrosis ${ }^{14-18}$ - but again there has been only one report in association with polycythaemia vera. ${ }^{4}$

Up to $15 \%$ of cases of polycythaemia vera may terminate in AML, and this is more common in patients treated with alkylating agents or ${ }^{32} \mathrm{P}$ than with venesection alone. ${ }^{5}$ In only three previous cases has granulocytic sarcoma been described in patients with polycythaemia vera. ${ }^{7}$ As in patients with other myeloproliferative disorders, particularly CGL, in whom granulocytic sarcoma develops, the prognosis is poor $^{67}$ because of subsequent acute leukaemia. Of the 


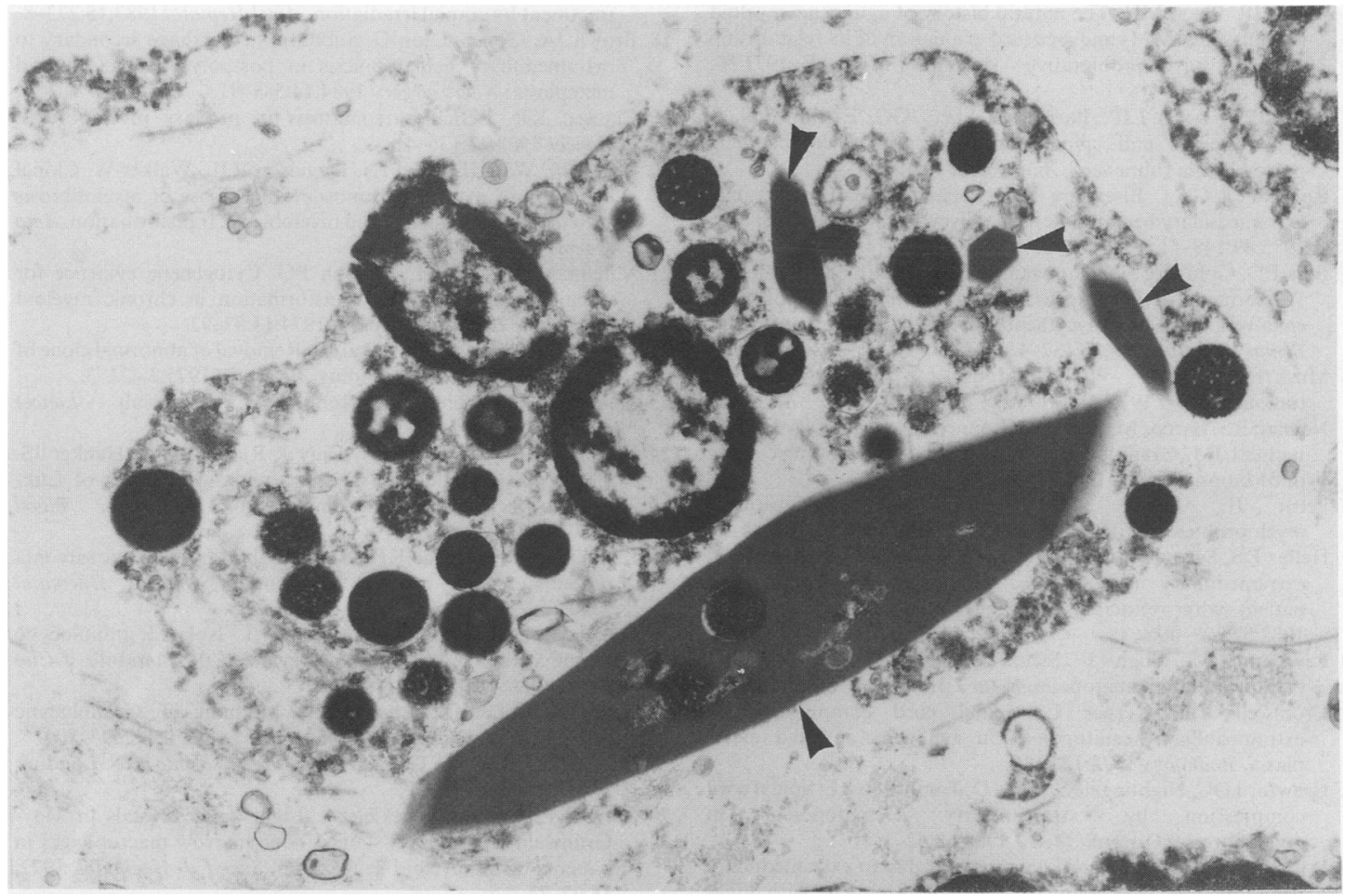

Fig 4 Electron micrograph of tumour cell with crystal-like inclusions seen in longitudinal section (arrowheads). Note structures present within largest crystal matrix.

three cases associated with polycythaemia vera, two developed AML within a month and the third developed a poorly defined myeloproliferative disorder one year later.

The development of granulocytic sarcoma within tumours of EMH is unusual, although there are reports of blast cell infiltration complicating EMH in primary myelofibrosis. ${ }^{1920}$ Cytogenetic evidence also suggests that blast transformation in chronic granulocytic leukaemia can originate in the spleen already affected by EMH. ${ }^{21}{ }^{22}$

The histological diagnosis of granulocytic sarcoma can be difficult. When the tumour occurs in the absence of other evidence of haematological disease it is often misdiagnosed as a high grade lymphoma. ${ }^{72-27}$ Cytochemistry is less helpful in undifferentiated tumours which are less likely to show extensive chloracetate esterase positivity. ${ }^{27}$ Ultrastructural examination can assist in making the diagnosis, and myeloblasts show a number of characteristic features. Primary granules of varying appearance are the most characteristic. 24 Auer rods are found within myeloblasts in about $10-20 \%$ of cases. They are needle shaped, peroxidase positive, and have a characteristic periodicity. ${ }^{28}$ Hexagonal and other geometric inclusions similar to those noted in this case have been reported in myeloblasts and macrophages of patients with myeloid leukaemia and preleukaemic states, ${ }^{29-31}$ but this seems to be the first report of such structures with crystal lattice planes within the tumour cells of a granulocytic sarcoma.

In conclusion, this case shows that discrete haemopoietic tumours, both of EMH and of granulocytic sarcoma, may complicate proliferative phase polycythaemia vera as well as other myeloproliferative disorders, and should be considered particularly when there are neurological complications.

We thank Professor J C McClure, Dr S S Banerjee, and Dr A Curry for helpful advice, Dr P Merry and the Artificial Limb and Appliance Centre, Withington Hospital for referring the patient and Dr A Jackson for performing the Tru-cut biopsy.

\section{References}

1 Adamson JW, Fialkow PJ, Murphy S, Prchal JF, Steinmann L. Polycythemia vera: stem cell and probable clonal origin of the disease. N Engl J Med 1976;295:913-6. 
2 Ward HP, Block MH. The natural history of agnogenic myeloid metaplasia (AMM) and a critical evaluation of its relationship with the myeloproliferative syndrome. Medicine 1971;50: $357-420$.

3 Rice GPA, Assis LJP, Barr RM, Ebers GC. Extramedullary hematopoiesis and spinal cord compression complicating polycythemia rubra vera. Ann Neurol 1980;7:81-4.

4 Robitaille GA, Eisenberg $M$, Lehman $R$. Intracranial extramedullary hematopoiesis in polycythemia vera. Conn Med 1985;49:149-51.

5 Berk PD, Goldberg JD, Donovan PB, Fruchtman SM, Berlin NI, Wasserman LR. Therapeutic recommendations in polycythemia vera based on Polycythemia Vera Study Group protocols. Semin Hematol 1986;23:132-43.

6 Muss HB, Moloney WC. Chloroma and other myeloblastic tumours. Blood 1973;42:721-8.

7 Neiman RS, Barcos M, Berard C, Bonner H, Mann R, Rydell RE, Bennett JM. Granulocytic sarcoma: a clinicopathologic study of 61 biopsied cases. Cancer 1981;48:1426-37.

8 Pettit JE, Lewis SM, Nicholas AW. Transitional myeloproliferative disorder. Br J Haematol 1979;43:167-84.

9 Heffez DS, Sawaya R, Udvarhelyi GB, Mann R. Spinal epidural extramedullary hematopoiesis with cord compression in a patient with refractory sideroblastic anemia. J Neurosurg 1982;57:399-406.

10 Lewkow LM, Shah I. Sickle cell anemia and epidural extramedullary hematopoiesis. Am J Med 1984;76:748-51.

11 Cromwell LD, Kerber C. Spinal cord compression by extramedullary hematopoiesis in agnogenic myeloid metaplasia. Radiology 1978;128:118.

12 Crawford DC, Nightingale S, Bates D, Tomlinson BE. Spinal cord compression by extramedullary haematopoiesis in myelofibrosis. Postgrad Med J 1984;60:62-3.

13 Price F, Bell H. Spinal cord compression due to extramedullary hematopoiesis. Successful treatment in a patient with longstanding myelofibrosis. JAMA 1985;253:2876-7.

14 Ligumski M, Polliack A, Benbassat J. Myeloid metaplasia of the central nervous system in patients with myelofibrosis and agnogenic myeloid metaplasia. Report of 3 cases and review of the literature. Am J Med Sci 1978;275:99-103.

15 Cameron WR, Ronnert M, Brun A. Extramedullary hemmatopoiesis of CNS in postpolycythemic myeloid metaplasia. $N$ Engl J Med 1981;305:765.

16 Lundh B, Brandt L, Cronqvist S, Eyrich R. Intracranial myeloid metaplasia in myelofibrosis. Scand J Haematol 1982;28:91-4.

17 Cornfield DB, Shipkin P, Alavi A, Becker J, Peyster R. Intracranial myeloid metaplasia: diagnosis by $\mathrm{CT}$ and $\mathrm{Fe}^{52}$ scans and treatment by cranial irradiation. Am J Hematol 1983;15:273-8.

18 Brown JA, Gomez-Leon G. Subdural hemorrhage secondary to extramedullary hematopoiesis in postpolycythemic myeloid metaplasia. Neurosurgery 1984;14:588-91.

19 Clausen KP. Reticulosarcomatosis in primary myelofibrosis. Cancer 1968;22:136-41.

20 Page BM, Watt JL, Reid IN, Davidson RJL, Walker W. Clonal evolution of marker chromosomes in a case of myelofibrosis with myeloid metaplasia and myeloblastic transformation. Acta Haematol 1979;61:301-9.

21 Mitelman F, Brandt L, Nilsson PG. Cytogenetic evidence for splenic origin of blastic transformation in chronic myeloid leukaemia. Scand J Haematol 1974;13:87-92.

22 Gomez G, Hossfield DK, Sokal JE. Removal of abnormal clone of leukaemic cells by splenectomy. $\mathrm{Br}$ Med J 1975;2:421-3.

23 Anonymous. Chloroma confusion. [Editorial]. Lancet 1973;i:1099-100.

24 McCarty KS Jr, Wortman J, Daly J, Rundles RW, Hanker JS. Chloroma (granulocytic sarcoma) without evidence of leukaemia: facilitated light microscopic diagnosis. Blood 1980;56:104-8.

25 Ersbøll J, Petri J, Jenson KH, Hansen MM. Granulocytic sarcoma preceding acute myeloid leukaemia. Scand J Haematol 1980;24:435-45.

26 Eshghabadi M, Shojania AM, Carr I. Isolated granulocytic sarcoma. Report of a case and review of the literature. J Clin Oncol 1986;4:912-7.

27 Meis JM, Butler JJ, Osborne BM, Manning JT. Granulocytic sarcoma in nonleukemic patients. Cancer 1986;58:2697-709.

28 Cawley JC, Hayhoe FGJ. Ultrastructure of haemic cells. London: WB Saunders, 1973.

29 Stavem P, Ly B, Bjorneklett A. Light green crystals in MayGrünwald and Giemsa-stained bone marrow macrophages in patients with myeloid leukaemia. Scand J Haematol 1977; 18:67-72.

30 Wolf DJ, Fialk MA, Mouradian J, Gottfried EL, Pasmantier MW. Unusual intracytoplasmic inclusions in acute myeloblastic leukemia. Am J Hematol 1980;9:413-20.

31 Nesland JM, Langholm R, Marton PF. Hexagonal crystals in the bone marrow in patients with myeloproliferative disease and preleukaemia. Scand J Haematol 1984;32:552-8.

Requests for reprints to: Dr P K MacCallum, Department of Haematology, Withington Hospital, West Didsbury, Manchester M20 8LR, England. 